The Impact of Teacher Intervention on Reaction to Aggression among Kuwaiti School Children 


\title{
The Impact of Teacher Intervention on Reaction to Aggression among Kuwaiti School Children
}

\author{
Amer Alsaleh $^{*}$
}

\begin{abstract}
Aggression in Kuwaiti schools remains a significant problem for educators. The present study examines the influence of teacher intervention on responses to classroom aggression. A sample of one hundred fifty teachers employed in twenty public schools across six governorates completed measures of teaching characteristics and responded to vignettes depicting student aggression. ANOVAs analyses were used to evaluate the process by which teachers respond to classroom aggression. The findings showed that teachers' response to aggressive behavior in the classroom was impacted by their prior training in classroom behavior management. Results confirmed the importance of prior training in supporting classroom management. Implications are discussed as they relate to relevant models and educational research initiatives. Future research should consider different facets of training programs (including both curriculum content and training methods) when considering the role of participation on teaching outcomes.
\end{abstract}

Keywords: Aggression, Elementary secondary education, Discipline, Proposed attributions, Affective reactions, Interventions.

\section{Introduction}

Aggressive behavior in schools remains a significant problem for both educators and the community as a whole both in the United States and around the world (e.g., Bauman \& Del Rio, 2005). Further, specific forms of aggression, such as peer bullying, continues to be a common problem

* professor of sociology, Kuwait university 
in many countries (Craig, Pepler, \& Atlas, 2000). Bullying is only one kind of school violence currently being researched. General violence in Kuwaiti high schools, for example, which is seen as severe, has recently drawn attention.

Newspapers have carried articles highlighting this violence and the types of weapons students bring to school. Statistics published by Kuwait's Ministry of Planning in 2000 gave the total Kuwaiti population as $2,228,363$ and the total number of violent crimes as 14,322 (Ministry of Planning 2001). The violent behavioral incidents registered in the record of Social Service Offices in public schools during the 2000-2001 academic years were 15,123 single student cases, out of a total student population of 264,408 . Some students were involved in more than one case (Ministry of Planning 2001:166). Of these cases, only 1,224 were reported to the police. In other words, violent crimes in Kuwait are nine times more likely to occur within the public schools' boundaries than in the outside community.

Although violence has been common in Kuwait throughout its history, researchers ask why violence happens more often within the boundaries of public schools. In addition, there is evidence of new types of violence, including using guns in fights and seeking immediate relatives' support in fights - all of which raise questions about the levels and causes of such violence. Clearly, there remains a need to better understand factors that predict, and ultimately lead to successful amelioration of, aggressive behavior problems.

\section{Research problem}

The question of this study was are the teachers with prior training would report greater likelihood of positive and less likelihood of negative affective reactions and interventions in response to the vignettes as compared to teachers without such characteristics. In fact, with training, gains are found in teachers' knowledge of behavior problems, application of training content, as well as more general effectiveness in classroom management and instructional strategies for use with problem students. This is demonstrated across studies that test implementation of specific interventions for classroom behavior problems (e.g., Allen \& Blackston, 
2003; Sawka, McCurdy, \& Mannella, 2002; Swinson \& Cording, 2002). In other words, teachers who are trained to be more effective in meeting both academic and non-academic student needs create a positive and successful classroom environment for all students. For instance, it is highly likely that teachers increase their knowledge about the aetiology, presentation, and treatment of behavior problems as a function of training. However, the impact of training on other factors related to intervention decisions (e.g., affective reaction to behavior problems) is not well understood.

\section{Studies of Violence in Kuwait: Gender Expectations and Education}

In 2000, the Ministry of Education surveyed a total of 100 male and female high school students from each of the five school districts in Kuwait to collect information about the amount and types of violence occurring in the public high schools. The study indicated that 40 percent of male students were physically or verbally abused by other male students, while 34 percent of female students were verbally or physically abused by other female students. The amount of violence varies, depending upon which system of education the students are enrolled in.

The study indicated that violence in the general system of education, in which students stay in the same classroom and take the same courses with the same teachers for the entire academic year (two semesters) is higher than in the credit-related system, which is relatively new (it was established in 1979). In the credit related system, which was extended to all school districts after the 1991 liberation of Kuwait from the Iraqi invasion, students change classes, classrooms, and teachers each semester, so that they are not consigned for an entire academic year to a class or teacher they might not like or one in which they have no friends. Students have the option to choose either system.

Although the difference between male and female school violence is expected due to the social and traditional expectations that limit females' actions, the extent of the violence is a major concern, because it is culturally supposed to be out of character for Kuwaitis, whose religion motivates them to be peaceful and helpful to others. Gender expectations play a significant role for both students and those in the labor force. While 
the government stresses the importance of education regardless of gender, most schools are segregated on the basis of gender after kindergarten.

Both Kuwaiti custom and law enforce a division of labor by gender. Unlike other Arabic countries, women are involved in various aspects of the labor force, although the percentage of women involved in labor outside of the home is small. Few women are owners or managers of even small businesses. Men and women do not have the same roles or status in Kuwaiti society, and there is tension between traditional Kuwaiti Islamic values and the values of the West. Many women still go veiled and wear the traditional black, while many girls in the younger generation follow the dictates of western fashion.

Female students are a majority at Kuwait University, and women are prominent in the country's commercial life and in the civil service. Women openly agitate for the relaxation of social restrictions on females, for more rights for women, and for an increase in job opportunities. These differences in expectations for the genders are clearly seen in the schools. All schooling for Kuwaitis is free, and between the ages of six and fourteen, attendance is compulsory. While the government stresses the importance of education regardless of gender, most schools are segregated on the basis of gender after kindergarten.

In many parts of the country, girls are still expected to prefer nurturing others to pursuing persona accomplishments, and these different expectations play out in the ways that children behave in school as well. Girls' antagonisms are expected to be expressed in gossip and social isolation of peers; boys still take out their aggressions in fighting and bullying.

\section{Literature Review}

Teachers endorse serious consequences of having aggressive youth in their classrooms. Student behavior and discipline problems (e.g., verbal disrespect, violence) are the primary reasons cited for teacher stress and burnout (Byrne, 1994; Friedman, 1995). Research has also shown that teachers' interactions with their students are negatively affected by their stress level, such that they use more harsh discipline and spend less time 
engaging students in a positive manner (Bibou-Nakou, Stogiannidou, \& Kiosseoglou, 1999; Capel, 1992).

The patterns of teacher-student interactions with aggressive children were similar to coercive parent-child relations that are frequently observed in families of aggressive youth. Parent-child interactions are the most factors in the social problems of children (Alvarado and Kumpfer).

Studies have produced empirical findings that indicate parental behavior can either increase or decrease an adolescent's risk for violence and other social problem behaviors (Elliot, Huizinga, and Menard, 1989; Patterson et al., 1992). For instance, research indicate that supportive parent-child relationships, positive discipline methods, close monitoring and supervision, parental advocacy for their children, and parental pursuit of needed information and support (Huizinga, Loeber, and Thornberry, 1995; Bry, 1996; Alvarado and Kumpfer, 2000).

Notably, this is quite disparate from the positive or neutral behavior management strategies typically used to address classroom behavior problems (Bibou-Nakou et al., 1999). Although recent researchers have drawn connections between teachers' perceptions about aggressive behavior and increases in coercive strategies (Bibou-Nakou et al., 1999; Poulou \& Norwich, 2000).

Furthermore, many schools do not have access to, or are not equipped to provide, the types of resources and services shown in the clinical literature to benefit aggressive youth. Kazdin (1995) also acknowledges that, even after appropriate treatment, many youth remain outside the normative range of functioning in home and school settings.

There also remain limitations in the long-term outcomes and the crosssituational success of intervention is not always evident (Dunn, Lochman, \& Colder, 1997; Frick, 2001; Offord \& Bennett, 1994). Given continued limitations in the existing school-based interventions for youth with aggressive behavior problems, numerous researchers suggest the need to shift research focus to factors that may influence intervention outcome in the school setting. 


\section{Teacher training Studies}

Research has demonstrated support for the importance of teacher training in the improvement of teachers' response to problem behavior and in the overall classroom environment. For instance, Cunningham and Sugawara (1988) found that teachers with no specialized training were more likely to endorse higher costs associated with behavior problems than were more advanced teachers. Teachers are also more accepting of, and more likely to employ, interventions that were viewed as less complex or better understood (Elliott, Witt, Galvin, \& Peterson, 1984). Greater facility with, and understanding of, non-academic issues would be expected as an outcome of specialized training in these areas.

Together, these studies also show that changes in teacher behavior as a result of training, in turn, lead to improvements in target student behavior problems and in the overall classroom environment more generally (Aarons, Sommerfeld, Hecht, Silovsky \& Chaffin, 2009; Dzuka \& Dalbert, 2007; Angelle, 2006).

Training for teachers can take many forms and can include specialized workshops and in-services, on-the-job mentorship and consultation, as well as academic coursework through a college or university. Despite the support for teacher training, this area of research remains relatively underrepresented in the literature. Furthermore, little is known about the process by which training relates to positive gains observed among teachers and their classrooms.

In a study by Merrett and Wheldall (1993) teachers reported that classroom management skills were of major importance to them professionally and approximately one-third felt that they had not received sufficient training in this area. Teachers also felt that additional training could reduce stress among teachers and behavior problems among students. Additionally, Kandakai and King (2002) found that pre-service teachers' confidence in teaching violence prevention to students was positively related to whether they had advanced certification in special education and/or specific training in violence prevention.

In order to understand the conditions under which contextual influences may impact affective and behavior al responses to aggressive behavior, it 
is helpful to consider possible processes by which certain factors impact those responses. According to early attribution theorists (e.g., Weiner, 1982) one's psychological and behavior al response could be understood as a function of certain attribution patterns. In particular, Weiner (1982) has shown that specific causal explanations fall along three main dimensions, namely locus of causality, controllability, and stability.

The relation between attributions and responses has been investigated in normative, academic, and clinical settings (e.g., Caprara, Pastorelli, \& Weiner, 1997; Clark \& Artiles, 2000; Georgiou, Christou, Stavrinides, \& Panaoura, 2002; Graham \& Weiner, 1991; Lopez, 1989). For instance, research has shown that aggression is more often judged by teachers to be caused by internal, stable, and controllable aspects of the child, which in turn elicits increases in negative relations and coercive strategies to address child behavior (Bibou-Nakou et al., 1999; Poulou \& Norwich, 2000). Together, these findings provide further support for the need to understand teachers' attributions of, and reactions to, classroom behavior problems, given the potential impact on their own behavior and that of others in the classroom context.

\section{Theoretical Perspective}

Weiner (2001) developed a theoretical model that specified the pathway from which a particular situational outcome initiates the attribution process. According to his model, the relation between a particular outcome and one's response to that outcome is mediated by the attributions formed about the outcome and the psychological reactions that were thought to result from those attributions. For example, if an adolescent boy has been exhibiting aggression since early childhood, his parents may assign high stability ratings, feel sad and hopeless, and, as a result, stop trying to make changes in his behavior.

Similarly, if these problems are viewed as under the intentional control of the boy, his parents may react by feeling angry. This, in turn, may lead to greater punishment and harsh discipline rather than seeking help and 
providing nurturance. This model has received extensive empirical support in normative populations (e.g., Caprara, Pastorelli, \& Weiner, 1997; Graham \& Weiner, 1991; Weiner, 1995; Weiner, \& Graham, 1999; Yirmiya \& Weiner, 1986). For instance, Graham and Weiner (1991) presented subjects with two vignettes of someone in need of aid, while manipulating information about the controllability of the person's need. Under the condition of high controllability, participants rated the outcome as more controllable, but also reported feeling more anger and less pity. Under this condition, they also indicated that would be less likely to help the target person. The current study focused on the investigation of professional training as a possible influence on teachers' response to aggressive behavior problems. In this study, perceived control was found to indirectly relate to likelihood of helping by way of changes in affect. Across all age groups this model was significant. Similar trends were found in the application of this model to professional settings. Struthers, Weiner, and Allred (1998) evaluated the fit of Weiner's model to predict personnel decisions for poor work performance among workplace supervisors.

\section{Objectives of the Study and Hypotheses}

The aim of the present study was to expand upon prior research related to aggressive behavior problems and teachers' classroom management experiences in Kuwaiti public schools. The current investigation was to examine whether teachers' proposed attributions, affective reactions, and interventions for aggressive classroom behavior vary as a function of differences in teacher training.

\section{Hypotheses}

It was hypothesized that teachers with prior training would report greater likelihood of positive and less likelihood of negative affective reactions and interventions in response to the vignettes as compared to teachers without such characteristics. 


\section{Method}

\section{Sample}

As part of this study, the sample for the study was randomly selected from eighty public elementary and middle schools in six governorates were solicited for participation. The random selection insures that every element in the population has an equal chance of being included in the sample.

This type of sampling was used because the schools are classified into six governorates: Alassima, AlFarwaniya, Aljahraa, Mubarak AlKabeer, AlAhmadi and Hawalli governorates. Each governorate represents one area of Kuwait City. Participants were treated in accordance with the "Ethical Principles of Psychologists and Code of Conduct" (American Psychological Association 1992).

A total of twenty schools agreed. Teachers who taught students in grades 5-8 were recruited from these twenty schools. Of the participating schools, 400 teachers were eligible for the project. A total of one hundred fifty eligible teachers signed consent and participated in the project. This sample consisted of 100 females (66.7\%) and 50 males (33.3\%). Participants ranged from 22 to 60 years old ( $M$ age $=42 ; \mathrm{SD}=11.00$ ). Relatively more teachers (i.e., $75.5 \%$ of the sample) reported that they had not received specialized training in classroom management. Of those who had received specialized training, $11.4 \%$ received training in one or more college classes, $8.9 \%$ participated in a workshop/in-service training, $7.1 \%$ received a specialized certification or degree, and $1.4 \%$ received on-thejob training.

\section{Measures}

Participants responded to a series of hypothetical vignettes of student aggression with measurements of proposed attributions, affective reactions, and interventions. Specifically, a teacher background questionnaire was developed by the experimenter to ascertain background demographic variables, including gender, grade taught by teacher, years of teaching experience, and nature of teacher training. 
For the purpose of this study, teacher training was considered as a possible contextual factor influencing responses to classroom aggressive behavior. Teacher training was operationalized as (a) "training in classroom behavior management techniques", or (b) "training in teaching techniques for children with emotional problems or emotional disabilities (ED)". Four written vignettes describing a child engaging in aggressive classroom behavior were developed by the experimenter for the current investigation.

Descriptions of the aggression subtypes reflect items on the Teacher Rating Scale (TRS) developed by Brown, Atkins, Osborne, and Milnamow (1996). Following each vignette, participants completed a questionnaire measuring their attributions and reaction to the child's behavior. This questionnaire format combined items from measures developed by Johnston and Leung (2001) as well as Poulou and Norwich (2000) who evaluated parent and teacher attributional patterns in British Columbia and Athens, Greece, respectively.

Questions about attributions were based on Johnston and Leung's work and questions about affective and behavior al reactions were adopted from Poulou and Norwich's questionnaire. Six possible affective reactions (i.e., stressed/anxious, helpless/depressed, hurt/offended, angry/resentful, sympathy/compassion, irritated) and six possible interventions (i.e., punishment, threats, support, refer for counseling, explanation of school rules, teacher education/learn more) were considered.

Teachers were asked to rate the degree to which each listed response would apply to their own likely reaction to the child (1=very unlikely to $10=$ very likely). For tests of moderation, the affective reaction of sympathy/compassion was used to reflect an empathetic emotional response and a composite of the angry/resentful and irritated reactions represented a negative/distress emotional response (Betancourt, Hardin, \& Manzi, 1992). Interventions were analyzed separately for all analyses given the qualitative differences in behavior al responses. 


\section{Procedure}

Data were collected between September 18, 2013 and Feb15, 2014 on site in each of these schools through administered survey that had been translated from English to Arabic, the native language of Kuwaiti, and from Arabic to English (Back translation) to be sure that the items translation was completed with the assistance of a professor in the English department at Kuwait University.To select one school in each governorate, the researcher wrote the names of schools on pieces of papers, and then a school was randomly selected from these governorates, giving each school an equal chance to be included in the sample. School principals from twenty schools in six governorates were first contacted by telephone describing the study and asking for school participation. A follow-up phone contact was initiated with school principals. Principals were of those schools that agreed to participate, either phone or in-person meetings were scheduled and held with each principal to describe the project and plan recruitment and project administration procedures.

Teachers were first introduced to the project by the school principal during a faculty meeting. At that time, the principal briefly discussed the focus of the project based on the wording used in the introductory letter. A meeting was held at each participating school with teachers in grades 5-8 and the experimenter. At this meeting, the project was described in greater depth. This included a detailed review of study consent, instructions, and assessments. In addition, interested teachers and school principals were provided a detailed synopsis of study findings and recommendations.

\section{Reliability and Validity}

In order to assess the reliability and validity of this study in local area, the coefficient alpha was high after the pilot study indicating high internal consistency and stability for all the scales in the present study, and validity which measure the operational definition and the concept is being measured interpreted within and support the theoretical 
framework of Weiner (2001) model.

In the present study, the alpha reliability score for attribution scales is .74. Affective reactions scales have a reliability alpha score of .82. Finally, the alpha reliability for the proposed intervention is.69.

\section{Results}

ANOVAs were used in order to test the hypothesis that teacher training had an impact on responses to aggressive classroom behavior, between-subjects. Teachers were asked to indicate whether they had received specialized training to work with ED students. Although no associations were found across attribution scales, main effects of training were found for affective reactions. Results are presented in Table 1. Generally, teachers with training endorsed significantly less negative effect in response to the hypothetical vignettes as compared to those with no training. Specifically, scores on anger, stress, helplessness, irritation, and hurt/offended scales were all significantly lower for trained teachers as compared to untrained teachers. Main effects of teacher training were also found across proposed interventions (see Table 1). First, as compared to those without ED training, participants with training believed that they would engage in more active, positive intervention strategies within the classroom including explanation of classroom rules and use of supportive behavior towards the child. Alternatively, untrained teachers were more likely to refer the child to outside personnel for services.

\section{Table1.}

ANOVAs

\begin{tabular}{|c|c|c|c|c|c|c|}
\hline \multicolumn{2}{|c|}{ Training } & \multicolumn{2}{|c|}{ No training } & \multirow{2}{*}{$F$} & \multirow{2}{*}{$\begin{array}{l}\mathbf{N} \\
\mathbf{D F}\end{array}$} & \multirow{2}{*}{ Sig } \\
\hline$M$ & SD & $M$ & SD & & & \\
\hline \multicolumn{7}{|c|}{ Affective reactions } \\
\hline
\end{tabular}




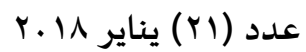

المجلة العربية لعلم الاجتماع

\begin{tabular}{|c|c|c|c|c|c|c|c|}
\hline & \multicolumn{2}{|c|}{ Training } & \multicolumn{2}{|l|}{ No training } & \multirow{2}{*}{$F$} & \multirow{2}{*}{$\begin{array}{l}\mathbf{N} \\
\mathbf{D F}\end{array}$} & \multirow{2}{*}{ Sig. } \\
\hline & $M$ & SD & $M$ & SD & & & \\
\hline Anger & 2.14 & 1.28 & 3.41 & 1.47 & 6.25 & $\begin{array}{l}N=148 \\
66.2\end{array}$ & 0.014 \\
\hline Stress & 2.25 & 1.45 & 5.02 & 1.36 & 7.80 & $\begin{array}{l}N=148 \\
67.4\end{array}$ & 0.003 \\
\hline Helplessness & 1.33 & 0.66 & 2.02 & 1.14 & 6.44 & $\begin{array}{l}N=148 \\
75.3\end{array}$ & 0.002 \\
\hline Irritation & 3.50 & 1.23 & 5.15 & 1.25 & 4.35 & $\begin{array}{l}N=148 \\
66.1\end{array}$ & 0.032 \\
\hline Hurt/offended & 1.06 & .064 & 2.30 & 1.46 & 4.89 & $\begin{array}{l}N=148 \\
56.6\end{array}$ & 0.012 \\
\hline & \multicolumn{7}{|c|}{ Proposed interventions } \\
\hline Punishment & 6.43 & 2.50 & 6.82 & 2.98 & 2.26 & $\begin{array}{l}N=148 \\
78.3\end{array}$ & 0.38 \\
\hline Threats & 4.90 & 1.96 & 5.17 & 1.79 & 1.29 & $\begin{array}{l}N=148 \\
74.3\end{array}$ & 0.48 \\
\hline $\begin{array}{l}\text { Explanation of school } \\
\text { rules }\end{array}$ & 7.22 & 1.89 & 7.98 & 1.76 & 2.85 & $\begin{array}{l}N=148 \\
72.1\end{array}$ & 0.20 \\
\hline Learn more & 4.12 & 2.20 & 5.84 & 2.33 & 5.28 & $\begin{array}{l}N=148 \\
79.2\end{array}$ & 0.04 \\
\hline Support & 6.34 & 2.69 & 5.24 & 2.14 & 3.42 & $\begin{array}{l}N=148 \\
78.8\end{array}$ & 0.05 \\
\hline Refer to counseling & 4.24 & 2.55 & 5.62 & 2.63 & 3.25 & $\begin{array}{l}N=148 \\
79.3\end{array}$ & 0.03 \\
\hline & & & $\begin{array}{l}75.5 \% \text { of the } \\
\text { sample }\end{array}$ & & & & \\
\hline
\end{tabular}

\section{Note:}




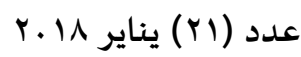

المجلة العربية لعلم الاجتماع

M: mean

SD: standard deviation Number of Sample $N=148$

\section{Discussion}

The goal of the present study was to evaluate and expand upon previous research on attributions of and responses to aggressive behavior in the schools and to better understand the impact of teacher training. The hypothesis was tested and supported by the data. Most teachers (i.e., $65.5 \%$ ) received a bachelor's degree; $34.9 \%$ and $1.8 \%$ received masters and doctorate degrees, respectively. Years of teaching experience ranged from 3 to 30 ( $M$ years=16.1; $S D=9.37)$.

The findings showed that teachers' response to aggressive behavior in the classroom was impacted by their prior training in classroom behavior management. Second, in an effort to identify processes that may help to explain teachers' response to classroom aggression, ANOVAs analyses were conducted to test the relation between teachers' proposed attributions, affective reactions, and interventions. Some have argued that characteristics of the perceiver, in addition to the target, impact the outcome of person perception processes.

Numerous researchers have considered a wide range of specific demographic, psychosocial, and professional characteristics that may relate to individuals' perception of others' behavior . In considering attribution processes specifically, the current study did not support the significant influence of training on teachers' attributions of classroom aggressions. Relatively more teachers (i.e., $75.5 \%$ of the sample) reported that they had not received specialized training in classroom management or for work with children having emotional problems. Of those who had received specialized training, $11.4 \%$ received training in one or more college classes, $8.9 \%$ participated in a workshop/in-service training, $7.1 \%$ received a specialized certification or degree, and $1.4 \%$ received on-the-job training. 
This is consistent with the work of Cunningham and Sugawara (1988) who evaluated causal attribution patterns and suggested disciplinary strategies for pre-service teachers. They showed that professional factors such as training related to differences in perceived costs associated with classroom behavior problems but not to the attributional judgment of the behavior itself.

The current study focused on the investigation of professional training as a possible influence on teachers' response to aggressive behavior problems. Results confirmed that prior training impacted both affective responses and behavior al reactions to the hypothetical vignettes of classroom aggression.

The data suggests that advanced training in behavior and/or emotional factors that impact classroom management may prove useful to general education teachers. Consistent with prior research (e.g., Cunningham \& Sugawara, 1988), teachers in the current study were more likely to report feelings of anger, stress, helplessness, irritation, and hurt/offence if they had not received prior training. It is also likely that teacher training has important effects on teachers' self-evaluation of competence, which in turn may impact responses to classroom management needs. Teacher training was also positively related to the likelihood that teachers would propose positive, active interventions in response to classroom aggression. This is also consistent with previous studies (e.g., Kandakai \& King, 2002; Schwartz, Wolfe, \& Cassar, 1997; Soodak \& Podell, 1997).

Internationally, a host of studies during the past few decades have demonstrated relations between teachers' perception of their students and the nature of interactions that take place in the classroom (e.g., Brophy \& Good, 1974; Clark \& Artiles, 2000; Georgiou et al., 2002; Kos, Richdale, \& Hay, 2006; Mavropoulou \& Padeliadu, 2002). Unfortunately, with few exceptions, most studies have focused on academic achievement and motivation rather than classroom management and non-academic deportment issues per se. Across studies, attributional theories have only 
been partially supported (e.g., Christenson, Ysseldyke, Wang, \& Algozzine (1993)). Further, Weiner (2001) acknowledges that the attribution of intentionality is also associated with a social and moral value judgment, which often elicits feelings of anger and a desire to hold someone personally responsible for their behavior. It seems probable that teachers who lack information about aggressive behavior problems and their treatment will feel greater demands, as students are exhibiting behavior that they likely perceive as highly deviant from their expectations, understanding, and/or comfort-level.

According to the attributional literature, attribution of stability regarding a target person's behavior is a key determinant in one's expectancy of success or failure in responding to that person (Weiner, 1985). In schools, the use of punishment often involves little effort or exchange on the part of the teacher, given the nature of punitive discipline methods. Indeed, Cunningham and Sugawara (1988) posit that punitive interventions serve to create distance or limit interaction between teachers and a problem child. Without training, a teacher may lack data about him/herself, such as knowledge of successful techniques and/or confidence in one's skills, which could offset the effects of stability attributions.

Furthermore, it is widely recognized that the legal system makes intervention decisions based on the stability of behavior. Interventions are viewed as less likely to work for stable behavior s or characteristics of a person (e.g., psychopathy) and, as a result, parole from jail is less likely for certain individuals deemed as having stable behavior problems (Carroll, 1986).

\section{Implications and Future Studies}

Extensive research in school-based mental health has shown that effective school-based interventions recognize and reinforce appropriate behavior to promote a positive school climate (e.g., DuPaul \& Eckert, 1997; Mayer, 1993); however, many school or classroom management 
procedures continue to be reactive, punitive, or control oriented (Furlong, Morrison, \& Pavelski, 2000).

Changes in teachers' classroom management approaches and school practices not only require a shift in philosophy about effective discipline but also adequate training to successfully engage in the new strategies. Although it may not directly relevant to a particular academic content area, classroom management skills are critical to the process of educating students across all content areas.

The expectations placed on teachers to manage a wide array of nonacademic behavior al needs in the classroom have important implications for both students and teachers. First, a range of personal and professional consequences for teachers who interact with, and address the needs of, problem students has been well documented (e.g., Burke \& Greenglass, 1995; Greene, Beszterczey, Katzenstein, Park, \& Goring, 2002). Second, teachers' functioning and student-teacher interactions have notable impact on student academic and social functioning for both the identified student as well as his/her peers in the classroom environment (Dornbusch, Erickson, Laird, \& Wong, 2001; Schwartz et al., 1997).

Bullying, teasing, and physical violence in the classroom can seriously disrupt student learning in many ways, such as lessening the amount of time available to teach a particular lesson, decreasing student attention to the teacher, and increasing student anxiety about future peer interactions.

Although recognition of the importance of teacher training to address non-academic barriers such as classroom management is not new to the field, this study offers findings that support continued investigation and advancement of training methodologies and content areas. Together, these findings highlight the importance of training which specifically focuses on more effective ways to promote accurate understanding and management of non-academic barriers associated with student emotional and behavior al problems. 
It also points to possible content areas within this line of training. For instance, it is widely recognized that teachers face the moment-to-moment responsibility of explaining students' past behavior and predicting students' future actions (Weiner, 1985). During the past few decades, researchers have gained interest in understanding the process underlying teachers' perceptions and responses to student behavior. As Weiner (2001) notes, judgments about a person's behavior is more commonly done when that person's behavior does not fit with the rules or expectations of the environment.

In a school setting, this may include exceptional academic performance, disciplinary infractions, and/or abnormal psychosocial functioning. Furthermore, teachers may benefit from training that builds selfawareness about this connection between their perceptions of, and reactions to, behavior ally challenging students. In addition, the current study highlighted the significant emotional costs of student aggressive behavior problems for teachers. This is consistent with previous research across the spectrum of behavior problems, noting the added burden of even more minor forms of behavior problems in the classroom. For instance, teachers recognize that children with ADHD tend to require added teaching time and classroom attention (Atkinson, Robinson, \& Shute, 1997). This, in turn, can result in a host of negative long-term outcomes such as increased absenteeism, impaired interactions with students and colleagues, and significant health consequences (e.g., Burke \& Greenglass, 1995).

It is possible that training in occupational stress management may help to curb the immediate and long-term effects of classroom behavior problems. In all, a combined training approach that addresses both student and teacher needs may prove effective in decreasing the negative effects of non-academic barriers, such as aggressive behavior, on student learning. This may involve helping to further develop teacher awareness of the characteristics and needs of students who may display aggressive behavior as well as techniques to effectively predict and prevent such 
behavior. As a complement, teachers may benefit from techniques to reduce personal bias about highly challenging students, address stress reactions when interacting with these students, and increasing awareness of their own strengths and limitations in the context of classroom management.

Future work in the area of teacher education should continue to explore strategies to enhance and improve training approaches, and in turn, the teaching experience more generally. This finding of the study underscores the context-dependent nature of both process and outcomes in schoolbased intervention. Indeed, interventions to address aggressive behavior that often avoid child-focused approaches and consider all aspects of the child's environment have been well supported in extant literature (e.g., Henggeler, Schoenwald, Rowland, \& Cunningham, 2002; Olweus, 1993). As such, we may find much success by moving beyond a one-size-fits-all approach to both the training and implementation of interventions for non-academic barriers such as classroom aggression. By considering the unique culture, needs and resources of students, teachers, school systems, and the community as a whole, it may be possible to streamline the training process.

In addition, teachers and administrators should carefully consider the context of research on topics such as classroom aggression and teacher training, as social norms, legal regulations, and school policies may fluctuate by community (both within and across different countries), resulting in varied teacher needs and resources within and outside the classroom. For instance, although peer aggression and bullying seems to be prevalent across the world, school districts in many countries still lack centralized policies and protocols that can help teachers know when and how to intervene (e.g., Kepenekci \& Cinkir, 2006). Research has shown that the training process is as important as its content in predicting training-related benefits in behavior al health (e.g., Hoge, Huey, \& O’Connell, 2004). 
Future research should consider different facets of training programs (including both curriculum content and training methods) when considering the role of participation on teaching outcomes. Finally, student aggression is a problem for a wide range of countries across the United States, Europe, Asia, and Australia (see Craig et al., 2000). Although this common problem may require unique intervention approaches depending on school and community contextual factors, we will likely continue to identify universal principles informed by psychological theory and research that helps to guide our efforts.

Indeed, future research initiatives should focus on both independent and collaborative work that better equips teachers, as well teacher educators, with successful strategies to reduce student aggression and promote a more positive and safe school climate. 


\section{$\underline{\text { References }}$}

1) Aarons, G., Sommerfeld, D., Hecht, D., Silovsky, J. \& Chaffin, M. (2009). The Impact of Evidence-Based Practice Implementation and Fidelity Monitoring on Staff Turnover: Evidence for a Protective Effect. Journal of Consulting and Clinical Psychology, 77(2), 270-280.

2) Allen \& Blackston (2003). Training Preservice Teachers in Collaborative Problem Solving: An Investigation of the Impact on Teacher and Student Behavior Change in Real-World Settings, School Psychology Quarterly 18, pp. 22-51.

3) Angelle, P. (2006). Instructional leadership and monitoring: Increasing teacher intent to stay through socialization. NASSP Bulletin, 90(4), 318334.

4) Alvarado, R Kumpfer, K.L (2000) Effective Family Strengthening Interventions. Bulletin. Washington, DC: U.S. Department of Justice, Office of Justice Programs Office of Juvenile Justice and Delinquency Prevention.

5) American Psychological Association (1992) "Ethical Principles of Psychologists and Code of Conduct." American Psychologist 47:15971611.

6) Atkinson, Robinson, \& Shute (1997). An Australian Perspective on Education of Children with ADHD, Educational and Child Psychology 14, pp. 21-30.

7) Bauman \& Del Rio (2005) S. Knowledge and Beliefs about Bullying in Schools: Comparing Pre-service Teachers in the United States and the United Kingdom, School Psychology International 26, pp. 428-44.

8) Betancourt, Hardin, \& Manzi (1992). Beliefs, Value Orientation, and Culture in Attribution Processes and Helping Behavior, Journal of CrossCultural Psychology 23, pp. 179-195.

9) Bibou-Nakou, Stogiannidou, \& Kiosseoglou (1999). The Relation Between Teacher Burnout and Teachers' Attributions and Practices 
Regarding School Behavior Problems, School Psychology International 20, pp. 209-217.

10) Brophy \& Good (1974). Good, Teacher-Student Relationships: Causes and Consequences, Holt, Rinehart and Winston Inc., New York.

11) Brown, Atkins, Osborne, \& Milnamow (1996). A Revised Teacher Rating Scale for Reactive and Proactive Aggression, Journal of Abnormal Child Psychology 24, pp. 473-481.

12) Burke \& Greenglass (1995). A Longitudinal Study of Psychological Burnout in Teachers, Human Relations 48, pp. 187-202.

13) Byrne (1994) B.M. Byrne, Burnout: Testing for the Validity, Replication, and Invariance of Causal Structure Across Elementary, Intermediate, and Secondary Teachers, American Educational Research Journal 31, pp. 645-673.

14) Bry, B. H. (1996). Reducing the Incidence of Adolescent Problems Through Preventive Intervention: One- and Five-Year Follow-Up. American Journal of Community Psychology, 10, 265-276.

15) Capel (1992) S.A. Capel, Stress and Burnout in Teachers, European Journal of Teacher Education 15, pp. 197-211.

16) Caprara, Pastorelli, \& Weiner (1997). Linkages Between Causal Ascriptions, Emotion, and Behavior, International Journal of Behavior al Development 20, pp. 153-162.

17) Carroll (1986). Causal Theories of Crime and Their Effect Upon Expert Parole Decisions. In: H.R. Arkes and K.R. Hammond, Editors, Judgment and decision making: An Interdisciplinary Reader, Cambridge University Press, New York, pp. 243-254.

18) Christenson, Ysseldyke, Wang, \& Algozzine (1993). Teachers' Attributions for Problems That Result in Referral for Psychoeducational Evaluation, Journal of Educational Research 76, pp. 174-179.

19) Clark \& Artiles (2000). A Cross-National Study of Teachers' Attributional Patterns. The Journal of Special Education 34, pp. 77-89.

20) Craig, Pepler, \& Atlas (2000). Observations of Bullying in the Playground and in the Classroom, School Psychology International 21, pp. 22-36. 


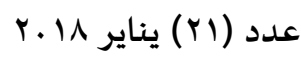

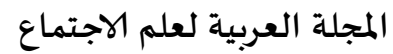

21) Cunningham \& Sugawara (1988). Preservice Teachers' Perceptions of Children's Problem Behavior s. Journal of Educational Research 82, pp. 34-39.

22) Dornbusch, Erickson, Laird, \& Wong (2001). The Relation of Family and School Attachment to Adolescent Deviance in Diverse Groups and Communities. Journal of Adolescent Research 16, pp. 396-422.

23) Dunn, Lochman, \& Colder (1997). Social Problem-Solving Skills in Boys with Conduct and Oppositional Defiant Disorders, Aggressive Behavior, pp. 457-469.

24) DuPaul \& Eckert (1997). The Effects of School-Based Interventions for Attention Deficit Hyperactivity Disorder: A Meta-Analysis, School Psychology Review 26, pp. 5-27.

25) Dzuka, J. \& Dalbert, C. (2007). Student violence against teachers: Teacherse well being and the belief in a just world. European Psychologist, 12(4), 253-260.

26) Elliott, D. S., Huizinga., and Menard (1989). Social Class and Delinquent Behavior in A national Youths Panel. Criminology, 21, 149-177.

27) Elliott, Witt, Galvin, \& Peterson (1984). Acceptability of Positive and Reductive Behavior al Interventions: Factors that Influence Teachers' Decisions, Journal of School Psychology 22, pp. 353-360.

28) Friedman, I. A. (1995). Student Behavior Patterns Contributing to Teacher Burnout. Journal of Educational Research, 88, 281-289.

29) Frick, P. (2001). Effective Interventions for Children and Adolescents with Conduct Disorder, Canadian Journal of Psychiatry 46, pp. 597-608.

30) Furlong, Morrison, \& Pavelski (2000). Trends in School Psychology for the 21st Century: Influences of School Violence on Professional Change, Psychology in the Schools 37, pp. 81-90.

31) Georgiou, Christou, Stavrinides, \& Panaoura (2002). Teacher Attributions of Student Failure and Teacher Behavior Toward the Failing Student, Psychology in the Schools 39, pp. 583-595.

32) Graham \& Weiner (1991). Testing Judgments about Attribution-EmotionAction Linkages: A lifespan Approach, Social Cognition 9, pp. 254-276.

33) Greene, Beszterczey, Katzenstein, Park, \& Goring (2002). Are Students with ADHD more Stressful to Teach? Patterns of Teacher Stress in an 
Elementary School Sample, Journal of Emotional and Behavior al Disorders 10, pp. 79-89.

34) Henggeler, Schoenwald, Rowland, \& Cunningham S.W (2002). Serious Emotional Disturbance in Children and Adolescents: Multisystemic Therapy, Guilford Press, New York.

35) Hoge, Huey, \& O’Connell (2004). M.A. Best Practices in Behavior al Health Workforce Education and Training, Administration and Policy in Mental Health 32, pp. 91-106.

36) Johnston \& Leung (2001). Effects of Medication, Behavior al, and Combined Treatments on Parents' and Children's Attributions for the Behavior of Children with Attention-Deficit Hyperactivity Disorder, Journal of Education 9, pp. 37-47.

37) Huizinga, D., Loeber, R., \& Thornberry, T. P. (1995). Recent Findings from the Program of Research on the Causes and Correlates of Delinquency (U.S. Department of Justice, Office of Justice Programs, Office of Juvenile Justice and Delinquency Prevention, NCJ 159042). Washington, DC: U.S. Government Printing Office.

38) Kandakai, T. L. \& King, K. A. (2002). Preservice Teachers' Perceived Confidence in Teaching School Violence Prevention. American Journal of Health Behavior, 26, 342-353.

39) Kazdin (1995). Child, Parent and Family Dysfunction as Predictors of Outcome in Cognitive-Behavior al Treatment of Antisocial Children, Behavior al Research and Therapy 33, pp. 271-281.

40) Kepenekci \& Cinkir (2006). Bullying Among Turkish High School Students, Child Abuse and Neglect: The International Journal 30, pp. 193-204.

41) Kos, Richdale, \& Hay (2006). Children with Attention Deficit Hyperactivity Disorder and Their Teachers: A Review of the Literature, International Journal of Disability, Development and Education 53, pp. 147-160.

42) Lopez (1989). Patient Variable Biases in Clinical Judgment: A Conceptual Overview and Some Methodological Considerations, Psychological Bulletin, pp. 184-203. 
43) Mavropoulou \& Padeliadu (2002). Teachers' Causal Attributions for Behavior Problems in Relation to Perceptions of Control, Educational Psychology 22, pp. 191-202.

44) Mayer, (1993). A Dropout Prevention Program for at-Risk High School Students: Emphasizing Consulting to Promote Positive Classroom Climates, Education and Treatment of Children 16, pp. 135-146.

45) Merrett \& Wheldall (1993). How Do Teachers Learn to Manage Classroom Behavior? A Study of Teachers' Opinions About their Initial Training with Special Reference to Classroom Behavior Management, Educational Studies 19, pp. 91-105.

46) Ministry of Planning (2001). Annual Statistical Abstract, 37th ed. Kuwait: Statistics and Information Sector.

47) Offord \& Bennett (1994). Conduct Disorder: Long-Term Outcomes and Intervention Effectiveness, Journal of the American Academy of Child and Adolescent Psychiatry 33, pp. 1069-1078.

48) Olweus, D (1993). Bullying at School: What We Know and What We Can Do, Blackwell Publishing, Malden, MA.

49) Patterson G. R., \& Kavanagh, K. (1992). An Experimental Test of the Coercion Model: Linking Theory, Measurement and Intervention. In J. McCord and R. Trembley (Eds.), The Interaction of Theory and Practice: Experimental Studies of Intervention (pp. 253-282). New York: Guilford Press.

50) Poulou \& Norwich (2000). Teachers' Causal Attributions, Cognitive, Emotional and Behavior al Responses to Students with Emotional and Behavior al Difficulties, British Journal of Educational Psychology 70, pp. 559-581.

51) Sawka, McCurdy, \& Mannella (2002). Strengthening Emotional Support Services: An Empirically Based Model for Training Teachers of Students with Behavior Disorders, Journal of Emotional and Behavior al Disorders 10, pp. 223-232.

52) Schwartz, Wolfe, \& Cassar (1997). Predicting Teacher Referrals of Emotionally Disturbed Children, Psychology in the Schools 34, pp. 5161. 
53) Soodak \& Podell (1997). Efficacy and Experience: Perceptions of Efficacy Among Preservice and Practicing Teachers, Journal of Research and Development in Education 30, pp. 214-221.

54) Struthers, C. W., Weiner, B., \& Allred, K. (1998). Effects of Causal Attributions on Personnel Decisions: A Social Motivation Perspective. Basic \& Applied Social Psychology, 20, 155-166.

55) Swinson \& Cording (2002). Assertive Discipline in a School for Pupils with Emotional and Behavior al Difficulties, British Journal of Special Education 29, pp. 72-75.

56) Weiner, F. (1982). An Attribution Theory of Motivation and Emotion, Series in Clinical and Community Psychology: Achievement, Stress, and Anxiety, pp. 223-245.

57) Weiner (1985). An attribution Theory of Achievement Motivation and Emotion, Psychological Review 92, pp. 548-573.

58) Weiner, B., \& Graham, S. (1999). Attribution in Personality Psychology, Pervin,Lawrence A. (Ed); John, Oliver P. (Ed). Handbook of personality: Theory and research ( 2 ed.). (pp. 605-628). New York, NY, US: The Guilford Press.

59) Weiner (2001). Responsibility for Social Transgressions: An Attributional Analysis. In: B.F. Malle and L.J. Moses, Editors, Intentions and intentionality: Foundations of social cognition, The MIT Press, Cambridge, MA, pp. 331-344.

60) Yirmiya, N., \& Weiner, B. (1986). Perceptions of Controllability and Anticipated Anger. Cognitive Development, 1, 273-280. 